\title{
LA ENSEÑANZA DE LA LENGUA ASTURIANA SEGÚN CONCEYU BABLE. DEMOCRACIA, AUTONOMÍA, IDENTIDAD Y NORMALIZACIÓN LINGÜÍSTICA EN LA ASTURIAS DE LA TRANSICIÓN (1974-1983)*
}

\author{
The teaching of the Asturian language according to Conceyu \\ Bable. Democracy, autonomy, identity, and linguistic \\ normalization in the Asturias of Transition (1974-1983)
}

\section{Marcos Rodríguez Álvarez ${ }^{\alpha}$}

Fecha de recepción: 06/06/2020 • Fecha de aceptación: 27/07/2021

Resumen. La aparición de Conceyu Bable en 1974, colectivo político-cultural de reivindicación lingüística, supone el inicio del movimiento moderno de recuperación de la lengua asturiana. El grupo rompe con el enfoque conservacionista desde el que se había abordado la promoción del asturiano hasta el momento para, reivindicándolo como código absoluto y unitario, promover su normalización social y política. Desde esta perspectiva, que entroncaba con las corrientes de demanda lingüística desarrolladas en el entorno próximo, la escolarización del idioma emergerá como objetivo prioritario del programa normalizador. Este artículo trata de desentrañar el marco conceptual que sustentó el discurso educativo de este movimiento, así como las ideas clave que para la inserción de la lengua asturiana en el sistema escolar fueron articuladas con ajuste al mismo. La demanda escolarizadora pivotará sobre razones de carácter político-cultural y de orden pedagógico. A caballo entre el tardofranquismo y la transición, la enseñanza del idioma será aireada por Conceyu Bable como una exigencia democrática, progresista y autonomista. De otro lado, analizando desde la sociolingüística la realidad asturiana como un

\footnotetext{
* Investigación financiada por el programa de Formación del Profesorado Universitario del Ministerio de Educación del Gobierno de España. MECD-17-FPU16/03535

${ }^{\alpha}$ Dpto. de Ciencias de la Educación, Facultad de Formación del Profesorado y Educación, Universidad de Oviedo. Campus de Llamaquique, C/ Aniceto Sela s/n, 33005 Oviedo/Uviéu, España. rodriguezamarcos@uniovi.es (D) https:// orcid.org/0000-0002-1482-3687
}

Cómo citar este artículo: Rodríguez Álvarez, Marcos. «La enseñanza de la lengua asturiana según Conceyu Bable. Democracia, autonomía, identidad y normalización lingüística en la Asturias de la Transición (1974-1983)». Historia y Memoria de la Educación 15 (2022): 479-511 
escenario de conflicto idiomático, se advertirá la necesidad de extraer al idioma autóctono del estado de marginalidad y rechazo escolar al que este se había sometido, proponiendo la transformación de la escuela como espacio de sensibilidad y respeto hacia la lengua asturiana y de promoción voluntaria de su alfabetización y conocimiento desde una enseñanza de enfoque científico.

Palabras clave: Enseñanza bilingüe; Reivindicación lingüística; Lengua asturiana; Conflicto lingüístico.

Abstract. The appearance of Conceyu Bable in 1974, a political-cultural collective of linguistic vindication, marks the beginning of the modern movement for the recovery of the Asturian language. The group broke with the conservationist approach from which the promotion of the Asturian language had been addressed until then, claiming the language as an absolute and unitary code and promoting its social and political normalization. From this perspective the schooling of the language emerged as a priority objective of its normalization. This article tries to unravel the conceptual framework that supported the educational discourse of this movement, as well as the key ideas for the insertion of the Asturian language in the school system that had to adjust to it. School demand revolved around political-cultural as well as educational considerations. Straddling late Francoism and the Transition, the teaching of the language was aired by Conceyu Bable as a democratic, progressive, and autonomous demand. On the other hand, analyzing Asturian reality from the perspective of a sociolinguistic scenario of idiomatic conflict, led the group to recognize the need to extract the native language from its marginalized condition and the rejection in schools that it had historically faced. Conceyu Bable proposed the transformation of the school as a sensitive and respectful space for the expression of the Asturian language and as an instrument capable of transmitting its literacy and knowledge from a scientific approach.

Keywords: Bilingual education; Linguistic claim; Asturian language; Linguistic conflict.

\section{INTRODUCCIÓN}

A lo largo de las últimas décadas viene desarrollándose dentro de la historia de la educación una línea de investigación centrada en los procesos escolarizadores de las diferentes culturas y lenguas propias de los territorios que componen el Estado español. Los estudios elaborados en torno a esta corriente, desvelando las distintas iniciativas educativas, sociales y políticas que, desde la modernidad hasta nuestros días, 
teorizaron y actuaron con el objetivo de hacer de la escuela un espacio permeable a las diferencias identitarias, han contribuido al conocimiento y comprensión del carácter pluricultural y plurilingüe que, con sus logros e insuficiencias, presenta nuestra actualidad escolar: la de una escuela cubista en una España cubista, que diríamos empleando la metáfora que en su día acuñara Luis Bello. ${ }^{1}$

El tardofranquismo y la Transición han concitado un especial interés dentro de este campo historiográfico, pues asistimos en estas etapas a la (re)aparición y afianzamiento de un conjunto de movimientos que reivindicarán la implementación de la enseñanza de las lenguas territoriales y emprenderán una labor de planificación y actuación pedagógica que marcará en buena medida la arquitectura de nuestro actual modelo educativo en su dimensión lingüística. Indudablemente, la atención a estos procesos ha encontrado mayor incidencia en aquellos territorios con movimientos de carácter nacionalista/regionalista de mayor arraigo sociopolítico y trayectoria cronológica. Entre otros, y por señalar solo algunos ejemplos, podríamos citar aquí los trabajos realizados por Jordi Monés $^{2}$ o González-Agàpito ${ }^{3}$ en el ámbito catalán, Pauli Dávila ${ }^{4}$ en el terreno vasco o Antón Costa $^{5}$ en el contexto gallego. Sin embargo, otras realidades específicas, como el caso de la asturiana, lengua que a pesar de carecer de estatus oficial se encuentra protegida por el Estatuto de Autonomía de 1981 y goza actualmente de implementación curricular en todas las etapas educativas no universitarias, han pasado más desapercibidas y son aún hoy desconocidas para gran parte de la comunidad académica y del público en general.

\footnotetext{
1 Ver Agustín Escolano, La España cubista de Luis Bello (Valladolid: Universidad de Valladolid, 2014).

2 Jordi Monés, «La renovació pedagògica a la postguerra en Catalunya (1950-1980)», Sarmiento 16 (2012): 57-71.

3 Josep González-Agàpito, «Dos formas de construir España: educación e identidad nacional. Una visión desde la cultura catalana», Historia de la Educación 27 (2008): 195-213; "Catalán o castellano: la alfabetización y el modelo de Estado", en Leer y escribir en España. Doscientos años de alfabetización, ed. Agustín Escolano (Madrid: Fundación Germán Sánchez Ruipérez, 1992), 141-163.

4 Pauli Dávila, «La renovación pedagógica en el País Vasco (segunda mitad del siglo XX)», Sarmiento 9 (2005): 85-103; Paulí Dávila y Ana Eizaguirre Sagardia, «Alfabetización y euskaldunización en Euskal Herria», en Leer y escribir en España, 187-211.

${ }^{5}$ Antón Costa Rico, "A escola que mudou: dinámicas, innovacións e experiencias na educación en Galicia (1961-2000)», Sarmiento 11 (2007): 7-36.
} 
Este estudio quiere profundizar en el inicio de la demanda escolarizadora de la lengua asturiana desde el novedoso planteamiento conceptual y discursivo que supuso en Asturias la irrupción del colectivo Conceyu Bable en 1974. Nuestro objetivo es describir y analizar la propuesta educativa elaborada por este colectivo, pionero en la reivindicación del asturiano desde presupuestos normalizadores, planteando un marco interpretativo de los vectores convergentes en la base de su articulación teórica. Nuestra investigación se apoya en fuentes documentales de distinta naturaleza, destacando el análisis de la producción escrita por Conceyu Bable en sus diversos canales de difusión y la revisión hemerográfica de los dos principales rotativos asturianos de la época ( $\mathrm{La}$ Nueva España y El Comercio), así como en la entrevista en profundidad a protagonistas destacados del proceso analizado, a modo de informantes clave.

Pretendemos con este estudio contribuir a complementar el mapa de los procesos de reivindicación e inserción de las lenguas propias en nuestro sistema educativo, que sin la concurrencia del fenómeno asturiano deja el puzle carente de una más de las piezas que conforman su compleja y rica diversidad.

\section{LA REIVINDICACIÓN DE LA ENSEÑANZA DE LAS LENGUAS TERRITORIALES EN EL TARDOFRANQUISMO: EL CASO ASTURIANO}

La década de los sesenta constituye un periodo de reactivación de las demandas lingüísticas en territorios del Estado español con lenguas propias diferentes a la castellana. Las redes sociales informales (sociedades culturales, colectivos vecinales, clubs deportivos...) jugaron a partir de estos años, fundamentalmente desde la promulgación de la Ley de Asociaciones de 1964, un determinante papel en la conservación y recreación de los idiomas propios. ${ }^{6}$ En el subterfugio que ofrecía el asociacionismo cívico y cultural, la concienciación lingüística encontró margen para su desarrollo y expansión, erigiéndose como elemento simbólico de unión y resistencia frente al aparato franquista. La reivindicación de las lenguas propias y la exigencia de mayor reconocimiento social y legal para las mismas se

\footnotetext{
${ }^{6}$ Xosé Manoel Núñez Xeisas, «Nuevos y viejos nacionalistas; la cuestión territorial en el tardofranquismo, 1959-1975», Ayer 68, no. 4 (2007): 59-87.
} 
vigorizaron en lugares como País Vasco, Cataluña y Galicia, conectando con las proclamas de oposición democrática contra el Régimen.

La incorporación de las lenguas territoriales a la enseñanza adquirió en este contexto gran protagonismo, tanto en el plano reivindicativo como en el de la práctica escolar. El movimiento de Ikastolas en País Vasco, la proliferación de las escuelas activas catalanas o la posterior aparición del Instituto Rosa Sensat son claro ejemplo de compromiso con la docencia de las lenguas propias en la semiclandestinidad, pero también con el despliegue de una acción educativa renovadora, democrática, plural y vinculada al entorno sociocultural que conformaron, en resumen, espacios educativos de contestación y resistencia antifranquista. ${ }^{7}$

No encontramos, sin embargo, un fenómeno de tales características en la Asturias de la década, donde la promoción de la lengua propia caminó por derroteros bien distintos. En 1969 el periodista y escritor José León Delestal promovía desde Madrid la creación de Amigos del Bable. Esta sociedad entroncaba con la tradición dialectizante, tendencia eminentemente cultural desarrollada desde el siglo XIX por ciertos sectores de la élite asturiana que mostraban, según la define San Martín, "procuro en el estudio, cultivo y defensa de "lo asturiano" [...]; pero entendido [...] como una simple manifestación particular de un verdadero todo sustantivo: "lo español"». ${ }^{8}$ En esta línea, los Amigos sumarán apoyos entre particulares interesados en la singularidad lingüística asturiana, a menudo relacionados con la Universidad de Oviedo y el Instituto de Estudios Asturianos (IDEA) — principales organismos de cultura oficial en la región-, que venían prestándole atención desde perspectivas antropológicas, dialectológicas y literarias, ahondando en la conceptualización del idioma como un código subdesarrollado, arcaico y fragmentado que únicamente encontraba valor como elemento subsidiario para el mejor conocimiento de las raíces del castellano, como vestigio de la Asturias tradicional o como mero entretenimiento folclórico. ${ }^{9}$

\footnotetext{
${ }^{7}$ Iñaki Zabaleta, Joxe Garmendia e Hilario Murua Cartón, «Movimiento popular y escuela en el franquismo: las ikastolas en Guipuzkoa», Historia de la Educación 34 (2015): 305-336; González-Agàpito, «Dos formas de construir España».

${ }^{8}$ Pablo San Martín, «La Doctrina Asturianista nel tiempu», en Vizconde de Campo Grande, Ceferino Alonso y José González, Doctrina Asturianista (Xixón: Fundación Nueva Asturies, 1999), 19.

${ }_{9}$ Andrea Geniola, «El nacionalismo regionalizado y la región franquista: dogma universal, particularismo espiritual, erudición folklórica (1939-1959)», en Naciones y Estado. La cuestión española,
} 
En comunión con esta idea, la actividad de Amigos del Bable no revestirá ningún tipo de pretensión normalizadora sobre el asturiano, limitándose a promover su tradición literaria y su investigación desde la óptica descrita. «Jamás he pretendido [...] que los asturianos vuelvan a hablar cotidianamente el bable de sus antepasados. Sí he intentado [...] que no desaparezca la literatura en bable, y que prosiga su creación», recalcaba Delestal, ${ }^{10}$ confirmando que el objetivo no era otro que desenvolver un conservacionismo del idioma puramente contemplativo.

Amigos del Bable expresará en diferentes ocasiones su intención de que el asturiano gozase de presencia en las escuelas, aunque circunscrita siempre a los parámetros que movilizaban la práctica y pensamiento del grupo. El acto que reúne mayor interés en torno a esta cuestión lo constituye la I Asamblea Regional del Bable, congreso de expertos y escritores en lengua asturiana organizado por la sociedad en 1973. Observamos en este encuentro un primer esfuerzo por analizar la situación de marginalidad educativa en la que se encontraba el idioma vernáculo y las consecuencias aparejadas a esta coyuntura, alertando de la fuerte interferencia lingüística que entre las lenguas castellana y asturiana presentaba el alumnado de la región y el profundo autoprejuicio que este manifestaba hacia la última. Con el objetivo de evitar tales efectos, se plantearán en la Asamblea posibles fórmulas para introducir el tratamiento del asturiano en las aulas, predominando una visión transicional en la que el idioma será observado como soporte didáctico, auxiliar y adaptativo, para el correcto aprendizaje de la lengua oficial, relegando su estudio a una actividad discrecional y folclórica. Su tratamiento educativo era abordado desde una concepción eminentemente diglósica que confería plena superioridad a la lengua castellana, al tiempo que la asturiana se presentaba como un código fragmentado para el que se delimitaban, a través de la práctica escolar, espacios específicos de uso anclados a contextos situacionales de cariz privado. ${ }^{11}$

eds. Ferran Archilés e Ismael Saz (Valencia: Universitat de València, 2014), 189-224; Rafael Rodríguez Valdés, «El bable y los bablistas. La paya nel güeyu axenu..., un documentu de Matías Conde», Lletres Asturianes 91 (2006): 39-68.

${ }^{10}$ Citado por Valentín Brugos, Conceyu Bable: venti años (Uviéu: Trabe, 1995), 61-62.

11 Ver Asamblea Regional del Bable, I Asamblea Regional del Bable: Actas (Madrid: Editorial Nacional, 1980). Para conceptos como diglosia, autoprejuicio u otros términos sociolingüísticos y su incidencia en Asturias ver p.e. Xosé Antón González Riaño, Manual de sociollingüística (Uviéu: ALLA, 2002). 
Paradójicamente, el acto convocado por Amigos del Bable serviría para poner en contacto a un grupo de jóvenes universitarios que compartían en torno al asturiano inquietudes notablemente alejadas, tanto en términos glotológicos como ideológicos, de los postulados tradicionales. En noviembre de 1974, fruto de las relaciones generadas a partir de aquel encuentro, nacía alrededor de Xosé Lluis García Arias, Lluis Xabel Álvarez y Xuan Xosé Sánchez Vicente el grupo Conceyu Bable, como una sección de la revista Asturias Semanal ${ }^{12}$ dedicada a temas de lengua, cultura y actualidad asturianas. La tribuna presentaba como principal novedad el uso y la reivindicación del idioma propio como código serio de expresión en el ámbito público. Lo que surge como una sección periodística elaborada por iniciativa de tres profesores superará en pocos meses los límites del papel para convertirse en un polo que concentrará a un grupo de personas interesadas en la demanda lingüística que, en 1976, acaba por registrarse oficialmente como asociación. ${ }^{13}$ Además del carácter movilizador y pedagógico que manifestaban los textos publicados en Asturias Semanal, los cursillos de lengua asturiana organizados en los principales núcleos poblacionales de la región durante el invierno de 1975 resultarían fundamentales para la expansión de Conceyu Bable como colectivo cívico. ${ }^{14}$

Aparece así el movimiento moderno de demanda y recuperación de la lengua asturiana. Una corriente popular que, a diferencia de iniciativas lingüísticas desarrolladas con anterioridad en la región, concebirá al asturiano como un idioma unitario, absoluto y moderno para el que se proyectará una acción normalizadora dirigida a desarraigarlo del estado

\footnotetext{
12 Sobre el importante papel informativo de la revista durante el tardofranquismo ver Cristóbal Ruitiña, Asturias Semanal. El nacimiento de un periodismo democrático (Xixón: Zahorí Ediciones, 2012).

13 Rafael Rodríguez Valdés, «Crónica de Conceyu Bable», en Conceyu Bable nes Fueyes Informatives (1976-1985), (Uviéu: Trabe, 2006), 9-27; Pablo San Martín, La nación (im)posible. (Uviéu: Trabe, 2006). El colectivo careció en lo orgánico de una estructura rígida, adoptando un modelo organizativo basado en el asambleísmo y la descentralización, de tal manera que los diversos grupos municipales que conformaban Conceyu Bable funcionaron con altos niveles de autonomía. Las acciones desenvueltas por la asociación fueron a menudo el resultado de la iniciativa y voluntariedad de un grupo reducido de integrantes altamente implicados que, por lo general, compaginaban su activismo conceyista con la militancia política, sindical o asociativa en otros terrenos. Entre otras cuestiones, esta fue causa del colapso que experimentó el colectivo hacia finales de los años setenta, llevándolo al cese de su actividad a mediados de los ochenta.
}

${ }^{14}$ San Martín, La nación (im)posible; Xulio Viejo, «Sociedá y discursu llingüísticu en Conceyu bable», en Conceyu Bable n'Asturias Semanal, (Uviéu: Trabe, 2004), 23-35; Patrick Zimmerman, Faer Asturies (Uviéu: Trabe, 2012). 
de exclusión y ostracismo en el que se encontraba y situarlo como código de uso válido para todos los ámbitos y niveles comunicativos. ${ }^{15} \mathrm{En}$ este sentido, junto a la normativización del idioma y su difusión en los medios de comunicación, la escolarización figurará como una proclama fundamental, para la que el grupo se esforzará en construir una base teórica, objeto de análisis en este artículo, que vendrá acompañada de una serie de acciones de concienciación y reivindicación social: los ya mencionados cursillos y, muy especialmente, la campaña de firmas $\mathrm{Ba}$ ble nes escueles, que reunirá en torno a treinta mil apoyos y desembocará en junio de 1976 en una manifestación que, bajo el eslogan Bable nes escueles. Autonomía Rexonal, congregará a unas seis mil personas en la que sería la primera concentración masiva y de carácter político de la restauración democrática en Asturias. ${ }^{16}$

Conceyu Bable supone un nuevo paradigma dentro de la tradición regionalista asturiana, al ser capaz de componer un discurso holístico que ubicará sus planteamientos en la estela de las tendencias de reivindicación lingüística de su contemporaneidad, íntimamente ligadas, como se ha comentado, con los movimientos populares de oposición democrática. ${ }^{17}$ Las actividades y propuestas de Conceyu se encuentran, pues, definidas por la asunción de un compromiso y una conciencia ideológicas para con la lengua asturiana que situarán su reivindicación como el epicentro de un programa más amplio, en el que se harán confluir, entorno a la cuestión idiomática, proclamas sociales, democráticas y autonomistas. ${ }^{18}$

\section{LA ENSEÑANZA DEL ASTURIANO EN CONCEYU BABLE}

El ámbito educativo será contemplado desde los inicios del movimiento como un campo estratégico de primer orden para asegurar el presente y futuro del asturiano. ${ }^{19}$ La escolarización de la lengua figura

\footnotetext{
15 Viejo, «Sociedá y discursu llingüísticu».

16 Para profundizar en estas acciones ver Zimmerman, Faer Asturies.

17 Conceyu Bable, «Alderique sol rexonalismu n'Asturies (I)», Fueyes Informatives 2 (1976): 16; Lluis Texuca, "Chando-i una güeyá al pasau. Qué ye y qué quier ser "Conceyu Bable"», Asturias Semanal 396 (1977): 38. Texuca es el sobrenombre del cofundador y líder de Conceyu Bable Lluis Xabel Álvarez.

${ }_{18}$ Conceyu Bable, «Nota sele. Bable y democracia avanzá», Asturias Semanal 356 (1976): 34. En adelante, la autoría de las referencias atribuidas a Conceyu Bable se consignará con las siglas CB.

19 CB, «A los enseñantes d'Asturies», Asturias Semanal, 296 (1975): 19.
} 
desde el primer momento como proclama fundamental de la reivindicación idiomática asturiana. Lo que en origen se presenta como la sencilla expresión de un anhelo, ${ }^{20}$ dará paso, en palabras de Sánchez Vicente, a la construcción de «una demanda de tipo racional, social y política. Las tres cosas [...]. La columna fundamental de la normalización lingüística». ${ }^{21}$

Así pues, a través de artículos en prensa, ponencias y manifiestos, Conceyu Bable irá moldeando su discurso de demanda de la enseñanza formal del asturiano. A la hora de analizar la propuesta conceyista, acertamos a identificar dos grandes ejes argumentativos relacionados entre sí: el que concentra, de un lado, los planteamientos de carácter pedagógico, y el que profundiza, de otro, en cuestiones de signo político-cultural.

\section{LOS SUPUESTOS POLÍTICO-CULTURALES}

Es posible observar, desde los primeros textos del colectivo, la fuerte presencia que en ellos encuentra la reivindicación de la lengua minoritaria como derecho. Que una de las primeras publicaciones del grupo consistiera, de hecho, en una icónica traducción al asturiano de la $D e-$ claración Universal de los Derechos Humanos ${ }^{22}$ no ha de verse como algo circunstancial. En esta línea, la demanda de escolarización del idioma se respaldó, en primera instancia, en la exigencia de dar cumplimiento a las resoluciones emitidas por la UNESCO referentes al amparo de las comunidades culturales a recibir enseñanza en y de su lengua propia..23 Haciendo suyas las palabras del sociolingüista gallego Xesús Alonso Montero, Conceyu Bable defendía que se trataba este del «derecho más radical: el que tiene un niño [...] a ser escolarizado en su idioma. Es un derecho [...] a no ser marginado, a no ser acomplejado, a no ser traumatizado». ${ }^{24}$

\footnotetext{
${ }^{20}$ Xosé Lluis García Arias. Entrevista realizada por el autor (Uviéu, febrero de 2019). Xuan Xosé Sánchez Vicente. Entrevista realizada por el autor (Xixón, febrero de 2019).

${ }^{21}$ Sánchez Vicente. Entrevista realizada por el autor.

22 CB, Declaración Universal de Drechos Humanos (Mieres: Conceyu Bable, 1975).

${ }_{23}$ Nos referimos a UNESCO, Empleo de las lenguas vernáculas en la enseñanza (1953) y UNESCO, Convención relativa a la Lucha contra las Discriminaciones en la Esfera de la Enseñanza (1960).

${ }^{24}$ CB, «Cartafueyu: les llingües llariegues», Asturies Semanal 339 (1975): 28. Todas las citas atribuidas a Conceyu Bable han sido traducidas del asturiano por el autor.
} 
Ahora bien, para el grupo este derecho educativo únicamente adquiriría una dimensión absoluta dentro de un proceso global de normalización sociopolítica del idioma que tan solo sería posible en el marco de un Estado democrático, progresista, plural y descentralizado. ${ }^{25}$ Así, del modo en que era definida por García Arias, la normalización de una lengua minorizada constituía «un trabajo profundamente democrático, en tanto en cuanto que trata de defender las manifestaciones de un pueblo». ${ }^{26}$ Un pueblo que tomaba además en la retórica conceyista su valor semántico más político, pues, de acuerdo con la construcción de su discurso, la regulación del idioma autóctono comprendía un conjunto de acciones y reconocimientos que afectaban de especial modo a las bases sociales de la región. Conceyu Bable dejaba ver sus influencias marxistas al afirmar que "la defensa y el desarrollo del asturiano es, antes que nada, la defensa de las clases populares que no hablan otra cosa y a las que no se puede avergonzar por ello». ${ }^{27}$

La reivindicación de la cultura asturiana, con la normalización de la lengua como núcleo de esta, se planteaba como alternativa popular frente al artificio de una cultura oficial establecida por el aparato franquista, de carácter elitista y uniformador, ${ }^{28}$ que, de un lado, hacía de las particularidades regionales objetos de estudio erudito y, de otro y al mismo tiempo, las trivializaba y deformaba para convertirlas en una irreconocible y folclorizada amalgama espectacular. Pero también frente al producto difundido por la industria cultural de masas, que el discurso conceyista censuraba como herramienta de un capitalismo igualmente esquilmador y homogeneizador. ${ }^{29}$ La democracia política por la que Conceyu Bable trabajaba no podía ser entendida si no era en estrecha conexión con una democratización cultural que superase la imposición de los artefactos derivados de una cultura dominante menguada y divulgada entre las bases; y ello pasaba, indefectiblemente, porque el pueblo

\footnotetext{
${ }^{25} \mathrm{CB}$, «Nota sele. Bable y democracia avanzá»; Xosé Lluis García Arias, Llingua y sociedá asturiana (Uviéu: Conceyu Bable, 1976).

${ }^{26}$ García Arias, Llingua y sociedá asturiana, 63. Traducido por el autor.

${ }_{27}$ CB, «Pa una defensa'l bable», Asturias Semanal 307 (1975): 16. Ver también CB, «Entamu. Conceyu Bable y la política», Asturias Semanal 367 (1976): 36.

${ }_{28}$ CB, «Cartafueyu'l VII Apautamientu Xeneral», Fueyes Informatives s/n (s/f, hacia enero de 1983): 25.

${ }_{29}$ CB, «Cartafueyu so'l rexonalismu», Fueyes Informatives 5 (1977): 7; «Cartafueyu'l VII Apautamientu Xeneral».
} 
asturiano fuese capaz de recuperar y dignificar su identidad cultural propia, se reconociera colectivamente en sus singularidades y tomase control sobre el cuerpo simbólico y el relato construido a partir de las mismas. ${ }^{30}$

Para el colectivo, la escuela debía erigirse como la base de esta democratización pues, como aún hoy enfatiza Lluis Xabel Álvarez, «en una lucha democrática por una actitud lingüística ecocultural [...] el gremio de maestros y maestras se hacía totalmente determinante».31 Era la institución escolar la que había de facilitar a los niños el conjunto de conocimientos y actitudes que les permitiesen entender y valorar adecuadamente su entorno cultural próximo y relacionarse con él. ${ }^{32}$ Era la escuela la que incorporando y naturalizando los elementos de la cultura autóctona en las aulas posibilitaría que la población asturiana los comprendiera y se comprendiese a sí misma en su identidad cultural propia. ${ }^{33}$ Era a través de una escuela plural y asturiana donde los niños podrían adquirir una conciencia de su lengua vernácula como elemento absoluto, pieza clave para asegurar la viabilidad futura de la misma. ${ }^{34}$ Era la escuela, en definitiva, la que debía cumplir este cometido porque la salvaguarda del patrimonio lingüístico y cultural asturiano constituía una responsabilidad pública, y no la tarea privada que el discurso hegemónico había pregonado, relegándola históricamente al ámbito exclusivamente doméstico y familiar. De la «lengua [autóctona], de su fortalecimiento o desaparición, es responsable [...] el pueblo asturiano — proclamaba Conceyu Bable - [por lo que] resulta evidente que los órganos de poder asturiano, deben hacerse responsables de los

\footnotetext{
${ }^{30}$ Ver CB, «Cartafueyu’l VII Apautamientu Xeneral», 25.

31 Lluis Xabel Álvarez. Entrevista realizada por el autor (Uviéu, junio de 2019). Traducido por el autor.

32 Lluis Xabel Álvarez, "La llingua asturiana, anguaño», en Informes y documentos. I Conceyu Asturianu de Profesionales (Uviéu: Comisión Organizadora del I Conceyu Asturianu de Profesionales, 1977), 24; CB, Llingua y cultura. Propuestes culturales al autogobiernu d'Asturies (Mieres: Conceyu Bable, 1978), 18-19; Xosé Lluis García Arias, «Lengua y cultura asturiana a la enseñanza: esbozo de un programa», Aula abierta 14 (1976): 48; Llingua y sociedá asturiana, 66-67.

${ }_{33}$ Corsino Fernández Viesca «¿Bable, pa qué y por qué? La cultura asturiana na escuela (6)», El Comercio, 2 de octubre de 1976. Fernández Viesca era un sobrenombre empleado por Sánchez Vicente.

34 Ver Conceyu Asturianu de Profesionales, «Primer Conceyu Asturianu de Profesionales», en Informes y documentos. I Conceyu Asturianu de Profesionales, 9.
} 
planteamientos lingüísticos que conciernen a nuestra sociedad». ${ }^{35} \mathrm{Y}$ entre ellos y en concreto, el concerniente al terreno educativo merecía especial atención. ${ }^{36}$

Así pues, al mismo tiempo que un derecho de los hablantes, la disposición de las medidas oportunas para garantizar el cumplimiento efectivo del mismo constituía un deber del que la sociedad asturiana en su conjunto, y por ende sus instituciones políticas, debían hacerse cargo. Por consiguiente, como principal institución social de transmisión cultural, la escuela debía incorporar tanto a su modelo curricular como al comunicativo la realidad lingüística asturiana, garantizándose de este modo el pleno cumplimiento del «derecho (y el deber) de las comunidades a mantener y alimentar su propia cultura; a mantenerla enseñándola, aprendiéndola y analizándola; a hacerla crecer empleándola y sirviendo de instrumento de trabajo a la comunidad». ${ }^{37}$

En este sentido, y sin renunciar a la posibilidad de contar con plataformas de titularidad particular, ${ }^{38}$ Conceyu Bable reivindicará un desarrollo de la escolarización del idioma encauzada de modo preferente a través de la red educativa pública. Las iniciativas de escolarización privada que se llevaban a cabo en Galicia, País Vasco y Cataluña resultaban a ojos del colectivo lingüístico asturiano una opción favorable para el desarrollo de una formación comprometida y vinculada con sus realidades específicas, frente a la negación o marginación que de las mismas se hacía en los programas oficiales de estudio. No obstante, según manifestaba Sánchez Vicente, «la enseñanza estatal es preferible (y hay que reclamarla) de todas todas [...], tanto porque ello no es más que un acto democrático [...], como porque para el Estado es más fácil organizar y programar este tipo de enseñanzas que para los particulares». ${ }^{39}$

Por otro lado, y como se deriva de toda la exposición anterior, lejos de ser vista únicamente como vehículo comunicativo, la lengua era

\footnotetext{
35 CB, Llingua y cultura, 3-4.

${ }^{36} \mathrm{CB}$, Llingua y cultura; García Arias, Llingua y sociedá asturiana, 53.

$37 \mathrm{CB}$, «Cartafueyu so'l rexonalismu», 6.

38 CB, «Nota sele», Asturias Semanal 317 (1975): 18; Fernández Viesca, "¿Bable, pa qué y por qué? Renacimientu, recuperación, esporpolle (3)», El Comercio, 4 de junio de 1976.

39 Fernández Viesca, «¿Bable, pa qué y por qué? (3)». Traducido por el autor.
} 
esencialmente para Conceyu Bable una herramienta conformadora de cultura y comunidad. ${ }^{40}$ Un escenario en el que se afrontaba la transición hacia un estado democrático, se discutía la arquitectura que este habría de presentar y se debatía el reparto de fuerzas internas que lo conducirían exigía, en concordancia con la lectura que el grupo hacía del mismo, una Asturias cohesionada y posicionada. De puertas hacia adentro, se requería una sociedad autoidentificada como pueblo singular, con proyecto de futuro propio y suficiencia de autogobierno para dirigirlo. De puertas hacia fuera, que la región fuese contemplada como una comunidad particular a la que se le reconocía capacidad y entidad para establecer y regir su propio marco político dentro de un estado descentralizado, considerándosela equitativamente en la toma de decisiones comunes al conjunto de pueblos que lo compondrían. ${ }^{41}$ Para Conceyu Bable la lengua autóctona era, indiscutiblemente, la levadura sobre la que había de fermentar el carácter singular y autónomo de Asturias como colectividad humana y política..$^{42}$ El planteamiento del grupo quedaba resumido en la sentencia «Asturies será en el futuro lo que sea su lengua»; ${ }^{43}$ lo que, a la inversa, significaba que la falta de normalización del idioma, su degeneración y pérdida definitiva, comprometía la viabilidad misma del pueblo asturiano como tal. ${ }^{44}$ La escolarización del idioma era determinante, pues, para expandir su conocimiento y asegurar su recuperación entre las nuevas generaciones, aquellas a las que les tocaría construir y consolidar el proyecto de una comunidad asturiana verdaderamente autónoma, progresista y con sentido identitario dentro de la España y la Europa de los pueblos que se ansiaban. El cómputo autonomía-clase-lengua-enseñanza quedaba bien sintetizado en palabras de Sánchez Vicente:

\footnotetext{
40 García Arias, Llingua y sociedá asturiana, 60-61.

${ }^{41}$ Ver Xosé Bolado García, "Asturies nuna república "federal” ", Fueyes Informatives 2 (1976): 9, 21; CB, «El principiu del nacionalismu y el fin de Conceyu Bable», Asturias Semanal 376 (1976): 36; «Cartafueyu so'l rexonalismu»; «Cartafueyu'l VII Apautamientu Xeneral»; Lluis Texuca, «Entamu al "Cartafueyu rexonalista d'Asturies" (Uviéu, 4 Febreru, 1977)», Asturias Semanal 401 (1977): 38.

${ }_{42}$ CB, «Cartafueyu'l VII Apautamientu Xeneral», 13. Ver también Álvarez, «La llingua asturiana, anguaño», 25.

${ }^{43}$ CB, «Cartafueyu'l VII Apautamientu Xeneral», 24.

${ }^{44}$ Ver García Arias, Llingua y sociedá asturiana, 87- 88.
} 
Hay razones de todo tipo [para introducir el bable en las escuelas] [...]. Vamos a explicar solo una de tipo político: el despertar de la lengua bable es la única forma que tenemos hoy de hacer una nacionalidad efectiva, de conformar un pueblo con conciencia colectiva [...]; sobre todo, de hacer una nacionalidad que mantenga por si misma su política y sus decisiones. [...] Una nacionalidad en el camino al socialismo. ${ }^{45}$

Merece la pena que nos detengamos un instante, antes de cerrar este apartado, en el punto que señalábamos más arriba: la alusión a la consecución de una Asturias autónoma encuadrada en una España y Europa de los pueblos. Si, como advertía García Arias, ${ }^{46}$ era esencial combatir los enfoques asimilistas que resultaban nefastos para la pervivencia del idioma propio, las posiciones denominadas como solipsistas, aquellas que practicaban una defensa grandilocuente y reduccionista de la lengua autóctona como principio y fin de todo lo que debía movilizar e interesar al pueblo asturiano, no suponían solución alguna al problema. La defensa que Conceyu Bable realizaba sobre su lengua se encaminaba a moldear y demandar una Asturias singular en lo cultural y autónoma en lo político, sí, pero vinculada comunitariamente con el conjunto de pueblos de su entorno próximo y remoto. ${ }^{47}$ Una unión que reposaba sobre motivos de índole económica y política, pero, fundamentalmente, sobre un principio de solidaridad intra e interestatal ${ }^{48}$ que llevaba al colectivo a plantear una defensa de la particularidad asturiana enmarcada siempre dentro de una relación de intercambio sociocultural con el resto de las comunidades. Así, concluía García Arias:

[la posición solipsista] no parece aceptable cuando lo que estamos apoyando y animando es el nacimiento de una convivencia de pueblos donde nadie sea el primero ni el excluyente. La atención a las lenguas minoritarias no puede aislarse de otros hechos

\footnotetext{
45 Xuan Xosé Sánchez Vicente, «El pelu de la dehesa al revés», La Nueva España, 5 de enero de 1978. Traducido por el autor. El término «nacionalidad» debe considerarse aquí dentro del debate surgido en torno a la terminología empleada en la Constitución Española, que hablaba de regiones y nacionalidades.

${ }^{46}$ García Arias, Llingua y sociedá asturiana, 56-59.

47 Ver García Arias, Llingua y sociedá asturiana, 89.

${ }^{48} \mathrm{CB}$, «Cartafueyu so'l rexonalismu», 8.
} 
históricos que hicieron que otras lenguas [...] se convirtieran en inter-lenguas útiles para la relación y el conocimiento de otras culturas. [...] Aprender todas las lenguas que podamos es bueno. ${ }^{49}$

Consecuentemente, la escuela asturiana, tal y como era proyectada por Conceyu Bable, tenía que cumplir la tarea de acercar e integrar al alumnado en la cultura autóctona, pero siempre desde una perspectiva aditiva y de diálogo intercultural con los otros.

\section{LOS SUPUESTOS PEDAGÓGICOS}

Visto hasta aquí el bloque concerniente a los planteamientos político-culturales, nos centraremos ahora en las tesis pedagógicas mantenidas por el colectivo. A este respecto, la preocupación de Conceyu Bable se fijará fundamentalmente en dos aspectos que, en realidad, ya habían sido puestos de relieve en la I Asamblea Regional del Bable, como eran los altos niveles de interferencia lingüística y autoodio hacia el idioma autóctono detectados entre el alumnado asturiano; si bien la interpretación y el tratamiento que va a proponer el grupo sobre estas dos cuestiones diferirá sustantivamente de lo expuesto en la Asamblea.

A diferencia del escenario dibujado por la tendencia conservacionista, para la que el contacto entre las lenguas castellana y asturiana se desarrollaba de acuerdo a un modelo de relación armónica en el que los espacios sociales que le correspondían a cada lengua venían determinados, de manera supuestamente lógica, por razones intrínsecas a la propia naturaleza evolutiva y expresiva de cada una de ellas, ${ }^{50}$ Conceyu Bable, inspirado fundamentalmente en las corrientes sociolingüísticas gallega y catalana, categorizaba la realidad asturiana como un contexto de conflicto lingüístico. ${ }^{51}$ La relación de desequilibrio existente entre los dos idiomas en contacto se encontraba mediada por un conjunto de tensiones y fuerzas de carácter histórico y sociopolítico, siendo precisamente esta realidad la que explicaba la aparición y los efectos de las interferencias y de las actitudes contrarias hacia la lengua propia.

\footnotetext{
${ }^{49}$ García Arias, Llingua y sociedá asturiana, 59, 72. En la misma línea CB, Llingua y cultura, 21.

50 Ver Asamblea Regional del Bable, Actas.

${ }^{51} \mathrm{CB}$, «A los enseñantes d'Asturies», 17; García Arias, Llingua y sociedá asturiana.
} 
Salvar las secuelas generadas por esta situación implicaba adquirir un conocimiento objetivo tanto de las lenguas en contacto como de las circunstancias que determinaban el estado de desigualdad que imperaba entre ambas..$^{52}$ De esta manera, si la Asamblea Regional del Bable, al partir de una concepción supremacista de la lengua castellana, reproducía en sus planteamientos educativos un patrón diglósico que contemplaba una atención escolar del asturiano desde una perspectiva vicaria con respecto al idioma legitimado, transicional y folclórica, Conceyu Bable reivindicará la enseñanza de la lengua autóctona por el valor que esta atesoraba en sí misma como instrumento vivo de comunicación y elemento nuclear de la cultura asturiana, postulando un modelo educativo conducente a alcanzar un bilingüismo equilibrado. ${ }^{53}$

Las argumentaciones de tono subordinador no desaparecerán, sin embargo, de manera drástica. En las primeras articulaciones del discurso conceyista continuará observándose cierta acomodación del aprendizaje del asturiano al del castellano que, en determinadas ocasiones, rayará con los argumentos que avalaban el carácter subsidiario manejados por los círculos conservacionistas. ${ }^{54}$ Debe tenerse en cuenta que algunos de los integrantes más influyentes del Conceyu habían participado activamente en la I Asamblea Regional del Bable y se habían formado en el círculo académico compuesto por algunos de sus promotores más destacados, ${ }^{55}$ de quienes se irían distanciando paulatinamente. Ello explica la existencia de lógicas influencias argumentativas en los primeros compases del movimiento. Asimismo, García Arias sostiene que el empleo de esta retórica atendía a una estrategia pragmática, cuyo uso en los inicios parecía aconsejable para introducir la cuestión y que, en cualquier caso, «incid[ía] en un aspecto práctico que en ningún caso agotaba todo el pensamiento». ${ }^{56}$

\footnotetext{
52 Ana María Cano et al., Gramática Bable (Uviéu: Ediciones Naranco, 1976), 17; Fernández Viesca «¿Bable, pa qué y por qué? (3)»; García Arias, Llingua y sociedá asturiana, 56.

53 Ver Conceyu Asturianu de Profesionales, «Primer Conceyu Asturianu de Profesionales», 8.

${ }^{54}$ Veáse, por ejemplo, Julio Ruymal, «"El bable, enseñando en la escuela, nos enseñaría a hablar y escribir mejor el castellano"», La Nueva España, 11 de enero de 1975; CB, «Pa una defensa'l bable»; Fernández Viesca «¿Bable, pa qué y por qué? (3)» o Lluis Fontetoba «¡Bable a la enseñanza!» La Voz de Asturias, 20 de junio de 1976. Lluis Fontetoba es un seudónimo utilizado por García Arias.

${ }_{55}$ Me refiero a García Arias y a Cano.

${ }^{56}$ García Arias. Entrevista realizada por el autor.
} 
En efecto, el planteamiento conceyista iba más allá. En líneas generales, Conceyu Bable se centrará ahora en reivindicar la alfabetización de la lengua asturiana al mismo nivel que la castellana, y junto a ella, como el medio más efectivo para lograr un reconocimiento adecuado del idioma autóctono y una discriminación de este frente al castellano y viceversa, favoreciendo de este modo el conocimiento y empleo de ambas lenguas y la desaparición de las interferencias mutuas. ${ }^{57}$ Así, como explicaba García Oliva:

Se parte de una situación diglósica, y se pretende que el niño aprenda las dos lenguas en conflicto, para que sepa discernir la una de la otra, sin interferencias, y emplee la que más le apetezca en cada momento. Que pueda optar por una o por otra con verdadero conocimiento de causa. ${ }^{58}$

El contraste entre el discurso normalizador y el conservacionista resultaba evidente. Para los segundos, el conflicto lingüístico que según los primeros caracterizaba la realidad bilingüe asturiana era falso, como así lo defendía uno de sus principales baluartes, el filólogo Jesús Neira. Según expresaba el profesor en la II Asamblea Regional del Bable, celebrada en 1975, el sistema educativo debía conseguir que la población asturparlante fuera capaz de diferenciar el idioma oficial de su habla local de empleo cotidiano, entendiendo que el primero constituía el patrón correcto de lenguaje. Así, la escuela debía «enseñarles castellano y decirles lo que no lo es [...] [, pues] solo el castellano, la lengua de todos, puede tomarse como la norma correcta». ${ }^{59}$ Desde la discriminación de los dos códigos en contacto, el alumnado podría utilizar cada uno de ellos con adecuación a las normas del supuesto consenso natural sobre el uso lingüístico alcanzado por la comunidad hablante a lo largo del devenir histórico; esto era, el castellano para las situaciones formales y el

\footnotetext{
57 Álvarez, «La llingua asturiana, anguaño», 24; Cano et al., Gramática Bable, 18; CB, «Notes Seles», Asturias Semanal 289 (1974); «A los enseñantes d'Asturies», 17; Llingua y cultura, 8; Fernández Viesca «¿Bable, pa qué y por qué? (3)»; García Arias, «Lengua y cultura asturiana a la enseñanza», 48; Llingua y sociedá asturiana, 51 .

${ }^{58}$ Xabel Ordiales, «Aclariando dos idees», El Comercio, 16 de julio de 1976. Xabel Ordiales, seudónimo empleado por el escritor y militante de Conceyu Bable Vicente García Oliva. Todas sus referencias han sido traducidas por el autor.

59 Jesús Neira Martínez, «El castellano, lengua de Asturias», La Nueva España, 18 de enero de 1976.
} 
asturiano para las relaciones familiares. ${ }^{60}$ En oposición, para Conceyu Bable la formación linguiística debía ofrecer a los escolares un tratamiento didáctico equitativo sobre las dos lenguas, desarticulando el mecanismo diglósico y favoreciendo así el empleo libre de ambos idiomas por parte del hablante, a quien los dos sistemas se le presentarían ahora con idéntico valor y capacidades expresivas y quien pasaría a disponer, tanto para uno como para otro, de las destrezas lingüísticas adecuadas para utilizarlas indistintamente en cualquier situación comunicativa, encontrándose en posición de decidir sin mediación de prejuicios sociales cuál de ellas deseaba emplear. ${ }^{61}$

Esta perspectiva dirigida al logro del bilingüismo equilibrado exigía un proceso de dignificación y normalización de la lengua asturiana en el aula. Es decir, era preciso deslindarla de la imagen hegemónica que la uncía al ámbito folclórico y al empleo privado y rústico, ${ }^{62}$ para pasar a proyectarla como un código perfectamente útil y apropiado para el conjunto amplio de las actividades comunicativas que en aquel momento le estaban exclusivamente reservadas al castellano, suministrando un aprendizaje de la misma consecuente con esta finalidad. ${ }^{63}$

Como señalaba Álvarez, «el valor del bable coloquial como "comunicación" no hac[ía] falta ponderarlo», lo preciso, continuaba, era "construir el valor comunicativo del bable culto».64 Reparaba así el autor en la necesidad de alfabetizar al alumnado en un asturiano formal. ${ }^{65} \mathrm{La}$ idea que movilizaba la praxis de los educadores conservacionistas propugnaba un tratamiento escolar de la singularidad lingüística asturiana enfocado en el activismo sobre elementos tópicos, ${ }^{66}$ vaciado de conteni-

\footnotetext{
60 Neira Martínez, «Castellano y bables, lenguas de Asturias (I)» La Nueva España, 17 de diciembre de 1975; «Castellano y bables, lenguas de Asturias (y II)», La Nueva España, 18 de diciembre de 1975.

61 Ver Ordiales, «Aclariando dos idees».

${ }^{62} \mathrm{CB}$, «Pa una defensa'l bable»; Fontetoba «¡Bable a la enseñanza!».

63 Álvarez, «La llingua asturiana, anguaño», 24.

64 Álvarez, «La llingua asturiana, anguaño», 24.

65 Sobre la reflexión en torno al asturiano formal o literario ver CB, «Entamu», Asturias Semanal 291 (1975): 20; «Entamu», Asturias Semanal 297 (1975): 16; «Nota sele ¡Asturianos, falai bable!», Asturias Semanal 353 (1976): 26.

${ }^{66}$ Recogida de vocabulario, refranes o historias entre la población anciana y rural, representación de escenas costumbrista, lectura de textos líricos y humorísticos de la literatura tradicional y
} 
do teórico y obstinado en mostrar una visión fragmentada de la misma como conjunto inconexo de hablas locales. Frente a ello, el movimiento normalizador aspiraba a configurar un asturiano estándar y su propuesta educativa abogaba por facilitar, en torno a este y con este como vehículo, ${ }^{67}$ una formación científica del idioma en sus parcelas gramatical, sociolingüística, literaria e histórica. Si el alumnado asturiano se encontraba tradicionalmente sometido a una enseñanza monolingüe castellana que adolecía de una total «ausencia de métodos lingüísticos y científicos que buscasen e iluminasen las peculiaridades de la lengua autóctona»,68 emergía con absoluta urgencia la necesidad de "acabar con la desinformación [...] [y] aplica[r] a nuestra lengua toda la terminología que acostumbramos a oír en la escuela, el instituto y la universidad para otras lenguas». ${ }^{69}$ Era este el rumbo a seguir para poner fin al estigma lingüístico que pesaba sobre el asturiano, pues un tratamiento educativo fundamentado resultaba esencial para modificar «la percepción psicoafectiva y, por ello, el grado de aceptación de un producto vestido ya con el mismo ropaje científico, produciendo de esta manera sus efectos sobre la conciencia del pueblo que habla esa lengua». ${ }^{70}$

Esta dimensión psicoafectiva conformaba, precisamente, un aspecto capital dentro del proceso normalizador. Como señalaba Sánchez Vicente, para que los y las hablantes bilingües de un idioma minorizado como el asturiano alcanzasen un reconocimiento total y equitativo de las dos lenguas contiguas no bastaba con que estos conociesen los elementos estructurales propios de ambas y fuesen capaces de discernirlos correctamente entre sí, se hacía al mismo tiempo imprescindible que adquiriesen la percepción de que la lengua minorizada constituía un código pleno y no una variante dialectal o un habla de segunda categoría. ${ }^{71}$ En

\footnotetext{
composición con ajuste a sus patrones, interpretación de canciones populares, etc. Ver Asamblea Regional del Bable, Actas.

${ }^{67}$ Fernández Viesca, «¿Bable, pa qué y por qué? La cultura asturiana na escuela (1)», El Comercio, 27 de agosto de 1976.

68 Álvarez, «La llingua asturiana, anguaño», 22.

69 Monchu Díaz, «Radiu n'asturianu», Lletres Asturianes 21 (1986): 172. Traducido por el autor. Militante de Conceyu Bable, Díaz ocupó el cargo de tesorero en la primera junta directiva de la asociación.

70 Díaz, «Radiu n’asturianu», 172.

${ }^{71}$ Fernández Viesca, «¿Bable, pa qué y por qué? (3)»
} 
oposición al planteamiento conservacionista que, según apuntaba Neira, respaldaba que «enseñar bien el castellano era el mejor medio para quitarles ese famoso complejo de inferioridad con el que ahora se quiere vestir, acomplejar a las gentes de nuestras aldeas», 72 la escolarización del asturiano junto y en equilibrio con el castellano suponía para Conceyu Bable la vía más adecuada para reforzar los niveles de lealtad lingüística hacia el idioma autóctono, desarticulando a través de la enseñanza los prejuicios que originaban las actitudes estigmatizadoras hacia la lengua propia y la conducían a su retroceso social. En palabras de Sánchez Vicente, «llevarlo a la escuela [al asturiano] era combatir su desprestigio [...]. Eran dos cosas: que la gente lo conociese y lo aprendiesen los niños y, al mismo tiempo, contrarrestar esa marginalidad social que tenía». ${ }^{73}$

Reconfigurar la escuela como un espacio plural y adaptado al entorno, en el que el alumnado pudiera expresarse con entera libertad en lengua asturiana sin recibir por ello ningún tipo de represión por parte del magisterio, se presentaba como una labor esencial para normalizar y dignificar el idioma, evitando la aparición de conductas de rechazo y autoodio hacia el mismo. ${ }^{74}$ "Cómo puede conservarse una lengua — se preguntaba Conceyu Bable- si no se enseña en la escuela, es más, si se reprime en la escuela como incorrecta y defectuosa, [...] cómo la gente va a hablarla sin vergüenza de no ser bien visto su uso». ${ }^{75}$ Así, más allá de exigir que la institución escolar cumpliese con la tarea trasmisora y alfabetizadora de un asturiano formal que, de acuerdo con los planteamientos del grupo, estaba obligada a desarrollar, la demanda de escolarización del idioma autóctono reclamaba poner freno al proceso de desaprendizaje activo que la escuela, como herramienta histórica de aculturación castellanizadora, llevaba a cabo con aquel alumnado para el que la lengua asturiana constituía ya su código habitual de comunicación. ${ }^{76}$

\footnotetext{
72 Neira Martínez, «El castellano, lengua de Asturias».

${ }^{73}$ Sánchez Vicente. Entrevista realizada por el autor.

74 Álvarez, «La llingua asturiana, anguaño», 23; CB, «Pa los maestros», Asturias Semanal 341 (1975): 16; «L'enseñanza'l Bable nes escueles y istitutos», Asturies Semanal 357 (1976): 27; Llingua y cultura; «Cartafueyu'l VII Apautamientu Xeneral»; Fontetoba «¡Bable a la enseñanza!».

${ }^{75}$ CB, «Respuesta de "Conceyu Bable" al artículo "Bable igual a babel”", Asturias Semanal 334 (1975): 25. En castellano en el original.

${ }^{76}$ Fernández Viesca, «¿Bable, pa qué y por qué? La cultura asturiana na escuela (4)», El Comercio, 18 de septiembre de 1976.
} 
García Arias, Sánchez Vicente y Álvarez, del mismo modo que una amplia nómina de quienes integraban Conceyu Bable, provenían del área rural o de los arrabales obreros de los principales núcleos urbanos de Asturias, aspecto que consideramos determinante en la formación y desarrollo del movimiento reivindicativo que nos ocupa. Los tres profesores se habrían criado en entornos sociofamiliares asturhablantes, adquiriendo el asturiano en su primera infancia, pero vivenciando más adelante el conflicto lingüístico durante sus primeros años de escolarización. ${ }^{77}$ Debían por ello conocer de primera mano la realidad coercitiva o despreciativa que hacia la lengua propia se desenvolvía de forma extendida en las aulas asturianas. Sería posteriormente, a lo largo de su etapa universitaria, cuando, apoyados en el marco teórico que les confería la confluencia de sus estudios, lecturas y adscripciones políticas, habrían emprendido una reflexión en torno a sus experiencias lingüísticas personales, tomando conciencia, tanto individual como colectiva, sobre la situación del asturiano. ${ }^{78}$ Una lengua que ahora eran capaces de reafirmar desde el juicio científico como un código de comunicación y cultura de carácter absoluto y cuya coyuntura podían analizar y comprender desde la teoría del conflicto lingüístico, nombrando y desentrañando los mecanismos escolares de represión idiomática y los efectos psicolingüísticos que estos generaban sobre las comunidades de habla minorizada. Este bagaje llevaría a los miembros de Conceyu Bable a reconocer la vital importancia que ocupaba la escolarización en el proceso de recuperación y normalización lingüística; la necesidad de naturalizar el idioma y dignificarlo en las escuelas para generar en estas modelos actitudinales positivos hacia el mismo, de los que ellos habían carecido, ${ }^{79}$ y acabar de esta manera con la desarticulación y autorrepresión idiomática que, a menudo, encontraba su origen en las mismas instituciones educativas. La enseñanza del asturiano supondría «la [...] rápida [...]

\footnotetext{
${ }^{77}$ El testimonio de Carlos Rubiera, militante de Conceyu Bable, narrando su propia experiencia de niñez resulta altamente esclarecedor. Ver Carlos Rubiera «Palabres de Carlos Rubiera», Lletres Asturianes 7 (1983): 7-10.

78 Ver entrevista a García Arias en SUATEA, «Entrevista», SUATEA 4 (1980): 6. Los conceyistas Lluis Xabel Álvarez y Pilar Fidalgo reafirman esta idea en las entrevistas que mantuvimos. Álvarez, Entrevista realizada por el autor; Pilar Fidalgo, entrevista realizada por el autor (Uviéu, abril de 2016).

79 «De aquella no había ni profesores, ni había gente con carreras, ni gente de nivel cultural alto que hablase en asturiano. No había modelo», señala Xosé María García «Llábana», activista de Conceyu Bable y uno de los primeros ocho maestros oficiales de asturiano. Xosé María García «Llábana», entrevista realizada por el autor (Xixón, mayo de 2016). Traducido por el autor.
} 
toma de conciencia por parte de la sociedad; el prestigio que emergería de la oficialización de la lengua (puesta de este modo a la misma altura que las demás asignaturas); la efectividad de no excluir la enseñanza de la cultura regional de la oficial». 80

\section{LA PROPUESTA EDUCATIVA CONCEYISTA}

Todos los aspectos hasta aquí referidos conforman el abanico de principios sobre los que se asentará el plan de enseñanza de la lengua asturiana esbozado por Conceyu Bable. Como indica Lluís Xabel Álvarez, «del mismo modo que hablamos de un proyecto "Rosa Sensat", aquí habría que hablar de la idea pedagógica "Conceyu Bable" en relación a la normalización escolar del asturiano».81 Ocuparemos las líneas siguientes en analizar las propuestas que comprendía este modelo bosquejado por el movimiento de reivindicación lingüística de Asturias.

Conviene advertir, en primer lugar, que el último de los aspectos aludido en el apartado anterior constituirá la principal preocupación del movimiento. Por encima de la configuración de una asignatura de lengua asturiana como tal, en los primeros textos de Conceyu Bable parece primar el interés por naturalizar la presencia del asturiano en el espacio educativo, la necesidad de generalizar entre el magisterio un conocimiento y una actitud de respeto y consideración hacia el idioma y hacia su libre empleo por parte del alumnado. De hecho, aunque la implementación del asturiano como asignatura voluntaria es una demanda presente en los primeros bosquejos del grupo, ${ }^{82}$ alcanzaría en un primer momento cierta dimensión la idea de que «llevar la lengua asturiana a la enseñanza [...] no debía [entenderse] necesariamente [como] la implantación de una materia más». ${ }^{83}$ Este enfoque inicial no significaba renuncia alguna a introducir en la escuela un tratamiento teórico-práctico de un asturiano formal; bien al contrario, ya hemos señalado la importancia que el grupo le otorgaba a este aspecto. La propuesta perfilada en los primeros momentos abogaba por que el asturiano fuera integrado

\footnotetext{
${ }^{80}$ Fernández Viesca, «¿Bable, pa qué y por qué? (3)».

81 Álvarez, entrevista realizada por el autor.

82 CB, «Carta a Asturies», Asturias Semanal, 328 (1975): 18.

${ }_{83} \mathrm{CB}$, Llingua y cultura, 8.
} 
en los niveles de Enseñanza General Básica y Bachillerato Unificado Polivalente dentro del área de Lengua española, que adquiriría ahora una dimensión plural. Se trataba de

Que una asignatura que siempre se llamó «Lengua Española», y que pretendía servir para que los niños aprendiesen a hablar y a escribir bien, cumpla el fin para el que está establecida. [...] Durante muchos años estuvieron ocultándonos la realidad, hablándonos solamente de «una lengua española» (el castellano), cuando lo cierto es que son varias las lenguas españolas. Dedicarle, por tanto, dentro de esa clase de aprendizaje de la lengua, una parte al castellano, y otra parte al bable, [...] para conocerlas de esta manera a ambas, no parece que vaya a ser nada perjudicial para los niños, sino todo lo contrario. ${ }^{84}$

La propuesta de Conceyu Bable se basaba en un modelo de bilingüismo aditivo ${ }^{85}$ en el que el aprendizaje de las lenguas castellana y asturiana correrían en paralelo dentro de la asignatura de Lengua, de tal manera que los contenidos teóricos que se trataban para uno de los idiomas habían de verse, correlativa y sinérgicamente, para el otro. En definitiva, se planteaba establecer un programa de estudios en el que la dedicación temporal a cada una de las dos lenguas se repartiera de forma ponderada dentro del mismo área de conocimiento, procurando con ello la consecución de los objetivos antes descritos: la adquisición de un bilingüismo equilibrado y la eliminación de las interferencias. ${ }^{86}$ En adición, el respeto al empleo del asturiano por parte del estudiantado y la atención docente hacia el idioma debía trascender las fronteras de la asignatura de Lengua y generalizarse en el resto de las materias escolares, así como en el conjunto de las relaciones comunicativas que se desarrollaban en los centros educativos. ${ }^{87}$

Por otro lado, y en consonancia con los objetivos normalizadores del grupo, se consideraba la del asturiano como una enseñanza cuya

\footnotetext{
${ }^{84}$ Ordiales, «Aclariando dos idees».

${ }^{85}$ Ver Jim Cummins, «Qué sabemos de la educación bilingüe? Perspectivas psicolingüísticas y sociológicas», Revista de Educación 326 (2001): 37-62; Lenguaje, poder y pedagogía (Madrid: Morata, 2002).

86 García Arias, «Lengua y cultura asturiana a la enseñanza», 48.

87 Álvarez, «La llingua asturiana, anguaño», 24; Fernández Viesca, «¿Bable, pa qué y por qué? (4)».
} 
impartición voluntaria convenía y debía extenderse a la globalidad del alumnado, fuera esta o no su lengua familiar. Se superaba desde esta perspectiva la visión de la lengua como problema, enfatizada por la tendencia conservacionista, y se iba más allá de una defensa de la lengua como derecho, que en sentido estricto circunscribía su docencia a la minoría hablante, para reivindicar el valor de la enseñanza del idioma autóctono como recurso sociocultural. ${ }^{88} \mathrm{El}$ colectivo defendía que enseñar asturiano al alumnado monolingüe castellano resultaba altamente favorable para su desarrollo, puesto que ensanchaba sus posibilidades de comunicación y relación con el conjunto de la comunidad, al tiempo que facilitaba su inclusión en el entorno próximo y mejoraba su capacidad para aprehenderlo y comprenderlo. ${ }^{89}$

Ahora bien, el abordaje de esta trasformación escolar y la introducción de estas prácticas docentes en torno al idioma autóctono precisaban de un magisterio correctamente capacitado para ello; exigencia que se incumplía en aquel momento. Una encuesta realizada entre el estudiantado de la Escuela Universitaria de Formación del Profesorado de EGB de Oviedo durante el curso 1976/77 mostraba que únicamente el 21\% entendía el asturiano, comprendiéndolo de modo parcial el 28\%, mientras que solo un $15 \%$ reconocía hablarlo y un $25 \%$ hacerlo parcialmente. ${ }^{90}$ La inexistencia de un profesorado adecuadamente formado en el conocimiento formal y didáctico de la lengua asturiana suponía un enorme hándicap de cara a la materialización del proceso escolarizador, como así se reconocía desde el movimiento lingüístico. ${ }^{91}$ Conceyu Bable exigirá por ello la implementación de estudios de asturiano en los títulos universitarios de filología y magisterio, con el objeto de dotar a los futuros docentes de las nociones y habilidades pedagógicas y filológicas necesarias para su correcta enseñanza. ${ }^{92}$

\footnotetext{
${ }^{88}$ Ver la clasificación de Ruíz acerca de la lengua como problema, derecho y recurso en Cummins, Lenguaje, poder y pedagogía.

${ }^{89}$ Fernández Viesca, «¿Bable, pa qué y por qué? La cultura asturiana na escuela (5)», El Comercio, 25 de septiembre de 1976.

90 Vivi Marquínez «Encuesta sol bable na Escuela maxisteriu», Fueyes Informatives 7 (1977): 3-5. Utilizamos esta encuesta a efectos puramente orientativos, pues no parece que la misma se hubiese realizado con rigor científico.

${ }_{91}$ CB «Xornaes pedagóxiques de llingües del Estáu Español», Asturias Semanal 360 (1976): 39; Llingua y cultura, 10; García Arias, "Lengua y cultura asturiana a la enseñanza», 49.

${ }_{92}$ CB, Llingua y cultura, 9; García Arias, «Lengua y cultura asturiana a la enseñanza», 48; Llingua y sociedá, 65.
} 
A este respecto, la referida encuesta recogía datos más favorables para los intereses del movimiento lingüístico, reflejando que el 85\% del estudiantado se mostraba partidario de la inclusión del idioma autóctono en las escuelas y que un $84 \%$ manifestaba que lo impartiría en caso de tener la posibilidad de formarse para tal efecto. ${ }^{93}$ Unido a ello, debía diseñarse un procedimiento de adaptación del profesorado en ejercicio mediante la articulación de cursos de sensibilización, divulgación y habilitación para la enseñanza del asturiano. ${ }^{94}$ Cabe reseñar el énfasis puesto por García Arias sobre la función concienciadora que, al respecto, debía asumir la Administración educativa, trasmitiendo al conjunto del profesorado el valor formativo y social de la lengua propia para motivar entre el cuerpo docente una actitud de corresponsabilidad hacia su normalización en las aulas y evitar que esta pudiera ser percibida como una medida arbitraria o impositiva..$^{95}$

Junto con la necesidad de hacer frente a la falta de capacitación del magisterio, otra cuestión que emergía con absoluta urgencia era la de solventar la ausencia de materiales pedagógicos. ${ }^{96}$ En este sentido, según observaba el grupo, no se trataba exclusivamente de resolver la carencia de recursos bibliográficos para la enseñanza de la lengua asturiana, sino que, más allá, debía lidiarse con la existencia de una profusa manualística de Lengua Española desfiguradora del idioma asturiano. ${ }^{97}$ La publicación en 1976 de la Gramática Bable confeccionada por un grupo de conceyistas, sin haber sido concebida en ningún caso por sus autores como un libro de texto para la impartición del asturiano en las aulas, ${ }^{98}$ dejaba ver entre sus páginas la clara vocación pedagógica con la que había sido elaborada, ${ }^{99}$

\footnotetext{
93 Marquínez «Encuesta sol bable».

94 Álvarez, «La llingua asturiana, anguaño», 24; CB, Llingua y cultura, 10; García Arias, "Lengua y cultura asturiana a la enseñanza», 49.

95 García Arias, «Lengua y cultura asturiana a la enseñanza», 49

96 CB, «Lletres en asturiano», Asturias Semanal 303-304 (1975): 18; "Xornaes pedagóxiques de llingües», 39; Llingua y cultura, 10; García Arias, "Lengua y cultura asturiana a la enseñanza», 49; Xabel Ordiales, "De palique con ún de los autores de la "Gramática Bable” ", El Comercio, 18 de septiembre de 1976; "Clasificar los problemas», El Comercio, 11 de marzo de 1977.

97 CB, «Notuca Sele. Llibros de testu con trampes», Asturias Semanal 335 (1975): 20; "Dellos escaecimientos», Asturias Semanal 338 (1975): 26.

98 Ver Ordiales, «De palique con ún de los autores».

99 Las alusiones a la cuestión educativa son numerosas a lo largo de toda la obra: en el prólogo de Alarcos Llorach, en los apuntes preliminares y en la justificación de algunas de las decisiones tomadas para la estandarización ortográfica del idioma. Ver Cano et al., Gramática Bable.
} 
y supuso una primera y fundamental referencia para aquellos sectores del profesorado comprometidos con el idioma.

A medida que la demanda escolarizadora y el desarrollo teórico que la sustentaba fueron adquiriendo cuerpo y notoriedad pública, comenzaron a arreciar voces opositoras a la misma. La heterogeneidad de la lengua asturiana fue un argumento empleado con frecuencia para rechazar la implementación de su enseñanza. La concepción del asturiano como un conjunto de hablas comarcales, fragmentadas y casi ininteligibles entre sí, que se venía planteando desde el siglo XIX y había constituido una de las ideas fuerza de la cultura oficial franquista, había sido una de las principales razones esgrimidas para justificar la supuesta inferioridad del idioma autóctono frente al oficial. Sin embargo, y al paso que el movimiento de reivindicación lingüística consolidaba sus posturas, la variedad diatópica fue puesta en alza desde ciertos sectores que, escudados en la defensa de un pretendido purismo idiomático, ${ }^{100}$ contradecían la escolarización del asturiano alegando que ello suponía la inculcación de una jerigonza de laboratorio que atentaba contra el mantenimiento de la riqueza lingüística que constituían las variantes locales. ${ }^{101}$

Ciertamente, Conceyu Bable trabajó en la elaboración de una norma asturiana basada en la variante central del idioma, formulando la ya citada Gramática Bable y unas Normes Ortográfiques del Bable. ${ }^{102}$ Pero el grupo también reiteró en numerosas ocasiones que el estándar propuesto no pretendía proscribir el empleo de las variantes locales, sino que únicamente fijaba una pauta escrita que, por otro lado, estaba presente en la impartición escolar de cualquier lengua moderna. ${ }^{103}$ De acuerdo

100 Si bien algunos conservacionistas secundaron desde un principio la incorporación del asturiano a las escuelas desde un tratamiento que prestase celosa atención a su variabilidad local, cabe advertir una defensa impostada de la diversidad oral del idioma entre un conjunto de voces que únicamente buscaban coartadas sobre las que amparar su radical oposición a la escolarización del mismo. Por esta razón hablamos aquí de un pretendido purismo.

101 Ver Escolín, «Bable, igual a babel», La Nueva España, 11 de octubre de 1975; Neira Martínez, «Castellano y bables (II)»; Francisco Sarandeses, «Bable ¿Cuál enseñarlo? ¿Quién?», La Nueva España, 16 de julio de 1976. Escolín se presentaba como un colectivo de personas anónimas interesadas por la cultura asturiana. Su trayectoria se limitó a la publicación de un puñado de artículos que polemizaban sobre los objetivos y actuaciones de Conceyu Bable. Sarandeses, miembro numerario del IDEA, fue un escritor en lengua asturiana, cultivador del verso humorístico principalmente.

${ }_{102}$ CB, Normes ortográfiques del Bable (Mieres: Conceyu Bable, 1978).

103 Ver Álvarez, «La llingua asturiana, anguaño», 24; CB, «Entamu», Asturias Semanal 291 (1975); Ruymal, «El bable, enseñando en la escuela». Incluso la propia Gramática. Cano et al., Gramática Bable. 
con esta visión, la propuesta escolarizadora del grupo trataba de conjugar la atención y respeto hacia la variante idiomática propia del área en la que se encontraba ubicado cada centro docente, es decir, la variedad de habla familiar del alumnado, con la enseñanza de un estándar y la trasmisión de una perspectiva del asturiano como código de extensión y unidad regional. De este modo, desde el movimiento de reivindicación lingüística se postulaba que la enseñanza de la lengua asturiana partiese, durante la etapa preescolar y el primer ciclo de la Enseñanza General Básica, de las variedades locales del idioma, para pasar en posteriores niveles al aprendizaje gradual de un asturiano normativo. Este debería centrar la enseñanza de la lengua autóctona en el Bachillerato y a él debía llegarse a través del progresivo acercamiento a las diferentes variedades lingüísticas, de tal modo que el alumnado pudiera reconocer el conjunto de convergencias reales entre todas ellas y la existencia, por tanto, de una lengua que, por encima de variaciones lógicas, presentaba una estructura definida y unitaria. ${ }^{104}$ Junto a la dimensión pedagógica debemos advertir aquí una estrategia de planificación lingüística. Como apuntaba Álvarez, en un proceso de normativización incipiente, el estándar debía presentarse en la escuela con progresividad para evitar extrañeza entre los y las hablantes y garantizar la adecuada aceptación de la norma escrita y la identificación social con la misma. ${ }^{105}$

Por otro lado, los círculos renuentes a la escolarización del asturiano trataron de presentar la demanda como el intento de una minoría de imponer una lengua artificial a través del sistema educativo. ${ }^{106}$ Desde el movimiento lingüístico se trató de contrarrestar este discurso negando de modo taxativo que la inserción del asturiano en las escuelas pretendiese

\footnotetext{
104 Álvarez, «La llingua asturiana, anguaño», 24; CB, «L'enseñanza’l Bable»; Llingua y cultura, 9; García Arias, «Lengua y cultura asturiana a la enseñanza», 48; Llingua y sociedá asturiana, 49-53.

105 Álvarez, «La llingua asturiana, anguaño», 24

106 El director de La Nueva España, Fernández Álvarez, señalaba que «estudiar el bable en las escuelas [...] equivaldría a que un tema anecdótico llegase a la apoteosis de coacción» y un editorial del rotativo tildaba su escolarización como el intento de «obligar a los neños [...] a obedecer bables "emprefabricados"». Faustino Fernández Álvarez, «El bable y la constitución», La Nueva España, 22 de noviembre de 1978; "Aclaración de Clarín sobre el bable unificado y polivalente». La Nueva Espa$\tilde{n} a, 19$ de junio de 1976. Por su parte, el director de El Comercio, Francisco Carantoña, quien se había expresado a favor de que las escuelas prestasen atención a la peculiaridad lingüística desde planteamientos conservacionistas, alertaba sin embargo del «peligro de que se intente fabricar un lunfardo, dirigido a eliminar el castellano, y a imponer [...] un idioma artificial y arbitrario». Till, "Sobre la presencia del bable en las escuelas», El Comercio, 28 de septiembre de 1979.
} 
constituir coacción alguna, recordando que el único idioma que ostentaba monopolio educativo era el castellano y que, por tanto, la contemplación del asturiano en las escuelas suponía, en rigor, el reconocimiento de la pluralidad idiomática que presentaba la realidad asturiana frente a lo que conformaba, en todo caso, la verdadera imposición excluyente: el establecimiento de un monolingüismo castellano sobre una comunidad en origen bilingüe. ${ }^{107}$ Sin embargo, el alcance mediático de las acusaciones lanzadas desde la oposición obligaban al grupo de reivindicación lingüística a operar con extrema prudencia y meticulosidad en cuanto al relato a emplear en torno al significado de introducir el idioma vernáculo en las aulas, habida cuenta de que lo que estaba en juego era la conceptualización que sobre la escolarización del asturiano arraigaría en el imaginario colectivo y conscientes de que, de consolidarse su percepción social como una imposición, sus posibilidades de desarrollo quedarían profundamente lastradas. Consecuentemente, Conceyu Bable apostó por un modelo de enseñanza basado en la libre elección, ${ }^{108}$ acompañado de programas de sensibilización social hacia el idioma. Como justificaba García Arias:

La sociedad asturiana irá aceptando, con total seguridad, la recuperación de una identidad asturiana si se le hacen ver sus ventajas, paulatinamente, y no con obligaciones trasnochadas y sin sentido en la formulación práctica. [...] Alejemos de nuestro lado posiciones maximalistas impositivas. Hagamos una política de atracción, racional, práctica, de hechos valiosos. ${ }^{109}$

\section{CONCLUSIÓN}

La aparición de Conceyu Bable constituye un punto de inflexión en lo referente a la concepción de la lengua asturiana y al planteamiento de

\footnotetext{
107 «Respecto al estudio del bable en las escuelas, no se quiere imponer nada, sino que se trata de todo lo contrario, de que no se le imponga al niño una lengua oficial, el castellano, en muchas ocasiones bastante alejada de la lengua que él emplea para hablar. [...] Es solo el reconocimiento de una realidad diaria». Ordiales, «Aclariando dos idees».

$108 \mathrm{CB}$, «Carta a Asturies»; «Xornaes pedagóxiques de llingües», 38.

109 Xosé Lluís García Arias, Llingua y sociedá asturiana, (Xixón: Comuña Lliteraria, 1984), 63. Se trata de la segunda edición, ampliada y corregida, de la obra originalmente publicada en 1976. El autor ocupaba ya en estas fechas el cargo de presidente de la Academia de la Llingua Asturiana, razón por la que en 1981 había abandonado la presidencia y militancia activa de Conceyu Bable. En cualquier caso, consideramos que el planteamiento expuesto sigue totalmente la línea discursiva conceyista.
} 
su reivindicación. El colectivo rompe con la tradición conservacionista y, definiendo a Asturias como un escenario de conflicto lingüístico y al asturiano como idioma vivo y absoluto, propone iniciar un proceso de recuperación y regularización del mismo con el objetivo de situarlo como lengua de uso en cualquier nivel y situación comunicativa. La demanda del idioma traspasa, además, la esfera de lo lingüístico y lo cultural para engarzar con lo político, vinculando la reivindicación de la lengua con las proclamas democráticas, autonomistas y progresistas. Esta novedosa concepción del asturiano y de su demanda supondrá la configuración de un nuevo paradigma, tanto analítico como proyectivo, en torno al tratamiento de su situación educativa. La escolarización del idioma se establece como uno de los elementos vertebradores del programa de recuperación lingüística, cuyo marco dimensional se resume en el siguiente cuadro.

\section{Cuadro 1. Marco conceptual sobre la escolarización del asturiano manejado por Conceyu Bable}

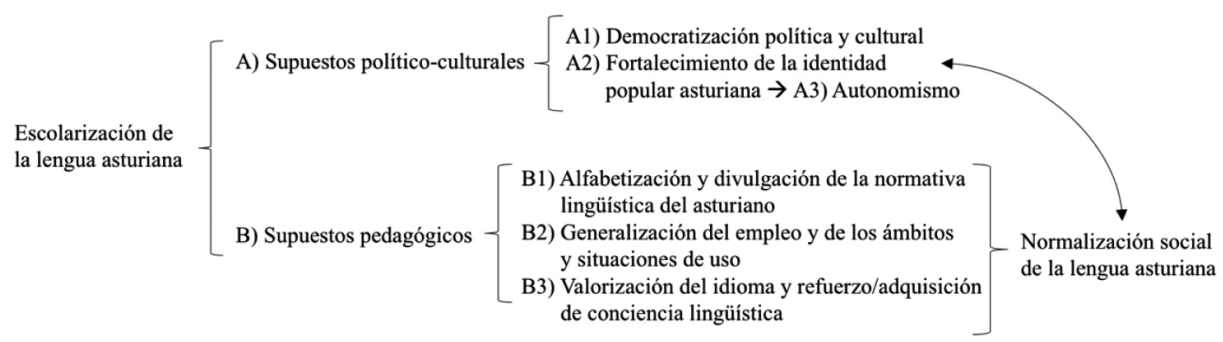

La demanda escolarizadora se sustenta, como hemos visto, sobre dos grandes supuestos: el político-cultural (A) y el pedagógico (B). Situados en el primero de los vectores, la enseñanza de la lengua propia se reclamaba como un derecho democrático que, consecuentemente, solo podría desarrollarse en plenitud dentro de un contexto de democracia política y cultural (A1), entendida esta última como el reconocimiento y revalorización de la cultura popular frente al constructo excluyente y subyugador confeccionado por las élites y el mercado. De otro lado, como elemento identitario, la lengua componía para el grupo el principal elemento de cohesión comunitaria (A2), fundamental para emprender el proyecto conformador de una Asturias democrática y autónoma enmarcada en una España y Europa de los pueblos (A3). Como principal institución de transmisión cultural, la escuela debía incorporar a su seno la enseñanza de la lengua autóctona, pues ello suponía, de un lado, 
la democratización cultural y lingüística de la institución docente y favorecía, de otro, la divulgación del conocimiento y aprecio del idioma entre los diferentes sectores de la población, potenciando ese arraigo comunitario.

En lo que refiere a la rama pedagógica, la escolarización del asturiano resultaba esencial para expandir la alfabetización de una lengua que, hasta el momento, había tenido un uso fundamentalmente oral y familiar, así como para facilitar a la población nociones sobre su estructura normativa (B1), presentándola como un código que reunía las mismas posibilidades expresivas que cualquier otro idioma, lo que hacía de él un instrumento válido y útil para cubrir cualquier necesidad comunicativa (B2). Pero, sobre esto, apremiaba abordar una reconfiguración del sistema educativo como un espacio armónico con la realidad bilingüe existente en Asturias, capaz de trasmitir al alumnado confianza y satisfacción en y por el empleo de su lengua propia, evitando así la aparición de autoprejuicios (B3). Estos tres elementos contribuían a la normalización social de la lengua, garantizando su supervivencia como idioma vivo.

Se producía, definitivamente, una relación sinérgica entre el apartado educativo y el político-cultural: una mayor normalización de la lengua a través de su enseñanza repercutía, de acuerdo con la visión conceyista, en mayores cotas democráticas y de conciencia autonómica, de la misma manera que un mayor desarrollo de estos dos niveles establecerían las condiciones ambientales favorables para el impulso del proceso de normalización idiomática.

Desde este marco conceptual el planteamiento educativo del asturiano se transforma. El valor de su conocimiento deja de medirse -al menos en exclusiva - en base a su potencialidad como auxiliar para el aprendizaje del idioma oficial y su tratamiento se desvincula de las perspectivas diglósicas que, como instrumento comunicativo, la ceñían al ámbito privado y rural y, como elemento lingüístico, limitaban su interés al de los campos antropológico y folclórico. El idioma propio pasa ahora a adquirir valor en sí mismo como lengua plena, buscándose la adquisición de un bilingüismo equilibrado. En correspondencia, y desde el respeto a la voluntariedad de su aprendizaje y a sus variedades geográficas, se abogará por adaptar el sistema educativo asturiano a la realidad plurilingüe del territorio y por introducir en él la enseñanza científica de 
una lengua asturiana estándar, con el objetivo de capacitar a la población para su libre empleo en el conjunto de las relaciones comunicativas y necesidades expresivas propias del mundo contemporáneo.

Como se ha señalado, Conceyu Bable complementará el desarrollo teórico que ha centrado la atención de este artículo con un conjunto de acciones formativas y reivindicativas que completarán la demanda escolarizadora. El camino abierto por el colectivo sería fundamental para que en el año 1981 el Estatuto de Autonomía del Principado de Asturias reconociera la promoción del idioma a través de su enseñanza voluntaria, y para que, con ajuste al mismo, la docencia formal del idioma se convirtiera en 1984, mediante su implementación experimental, en una realidad tangible.

\section{Nota sobre el autor}

MARCOS RODRÍGUEZ ÁLVAREZ es titulado en Ingeniería Técnica Industrial (2011), Máster en Formación del Profesorado de Educación Secundaria Obligatoria, Bachillerato y Formación Profesional (2012) y graduado en Pedagogía (2016) por la Universidad de Oviedo. Es doctor en Pedagogía (2021) por la Universidad de Oviedo con una tesis titulada «El proceso histórico de escolarización de la lengua asturiana: dimensiones políticas y sociales», que fue financiada con una ayuda Severo Ochoa de la Consejería de Educación y Cultura del Principado de Asturias (2017) y una ayuda para la Formación del Profesorado Universitario (FPU) del Ministerio de Educación, Cultura y Deporte del Gobierno de España (2017-2020).

Ha trabajado como profesor asociado en el Departamento de Ciencias de la Educación de la Universidad de Oviedo durante el curso 20162017, como investigador predoctoral entre 2017 y 2020 y desde entonces y hasta la actualidad como profesor interino. Es miembro de la Sociedad Española de Historia de la Educación (SEDHE).

\section{REFERENCIAS}

Brugos, Valentín. Conceyu Bable: venti años. Uviéu: Trabe, 1995.

Cano, Ana María et al. Gramática Bable. Uviéu: Ediciones Naranco, 1976. 
Costa Rico, Antón. «A escola que mudou: dinámicas, innovacións e experiencias na educación en Galicia (1961-2000)». Sarmiento 11 (2007): 7-36.

Cummins, Jim. «Qué sabemos de la educación bilingüe? Perspectivas psicolingüísticas y sociológicas». Revista de Educación 326 (2001): 37-62.

Cummins, Jim. Lenguaje, poder y pedagogía. Madrid: Morata, 2002.

Dávila, Pauli. «La renovación pedagógica en el País Vasco (segunda mitad del siglo XX)» Sarmiento 9 (2005): 85-103.

Dávila, Paulí y Ana Eizaguirre Sagardia. «Alfabetización y euskaldunización en Euskal Herria». En Leer y escribir en España. Doscientos años de alfabetización, dirigido por Agustín Escolano, 187-211. Madrid: Fundación Germán Sánchez Ruipérez, 1992.

Escolano, Agustín. La España cubista de Luis Bello. Valladolid: Universidad de Valladolid, 2014.

García Arias, Xosé Lluis. Llingua y sociedá asturiana. Uviéu: Conceyu Bable, 1976. García Arias, Xosé Lluis. Llingua y sociedá asturiana. Xixón: Comuña Lliteraria, 1984.

Geniola, Andrea. «El nacionalismo regionalizado y la región franquista: dogma universal, particularismo espiritual, erudición folklórica (1939-1959)». En Naciones y Estado. La cuestión española, editado por Ferran Archilés e Ismael Saz, 189-224.Valencia: Universitat de València, 2014.

González-Agàpito, Josep. «Catalán o castellano: la alfabetización y el modelo de Estado», En Leer y escribir en España. Doscientos años de alfabetización, dirigido por Agustín Escolano, 141-163. Madrid: Fundación Germán Sánchez Ruipérez, 1992.

González-Agàpito, Josep. «Dos formas de construir España: educación e identidad nacional. Una visión desde la cultura catalana». Historia de la Educación 27 (2008): 195-213.

González Riaño, Xosé Antón. Manual de sociollingüística. Uviéu: ALLA, 2002.

Monés, Jordi. «La renovació pedagògica a la postguerra en Catalunya (19501980)», Sarmiento 16 (2012): 57-71.

Núñez Xeisas, Xosé Manoel. «Nuevos y viejos nacionalistas; la cuestión territorial en el tardofranquismo, 1959-1975». Ayer 68, 4 (2007): 59-87.

Rodríguez Valdés, Rafael. «El bable y los bablistas. La paya nel güeyu axenu..., un documentu de Matías Conde», Lletres Asturianes 91 (2006): 39-68.

Rodríguez Valdés, Rafael. «Crónica de Conceyu Bable». En Conceyu Bable nes Fueyes Informatives (1976-1985), 9-27. Uviéu: Trabe, 2006.

Ruitiña, Cristóbal. Asturias Semanal. El nacimiento de un periodismo democrático. Xixón: Zahorí Ediciones, 2012.

San Martín, Pablo. «La Doctrina Asturianista nel tiempu». En Vizconde de Campo Grande, Ceferino Alonso y José González, Doctrina Asturianista, 8-66. Xixón: Fundación Nueva Asturies, 1999. 
San Martín, Pablo. La nación (im)posible. Uviéu: Trabe, 2006.

Viejo, Xulio. «Sociedá y discursu llingüísticu en Conceyu bable». En Conceyu Bable n'Asturias Semanal, 23-35. Uviéu: Trabe, 2004.

Zabaleta, Iñaki; Joxe Garmendia e Hilario Murua Cartón. «Movimiento popular y escuela en el franquismo: las ikastolas en Guipuzkoa», Historia de la Educación 34 (2015): 305-336.

Zimmerman, Patrick. Faer Asturies. Uviéu: Trabe, 2012. 